\title{
The effects of exposure to repeated minor pain during the neonatal period on formalin pain behaviour and thermal withdrawal latencies
}

\author{
C Celeste Johnston RN DEd, Claire-Dominique Walker PhD
}

CC Johnston, C-D Walker. The effects of exposure to repeated minor pain during the neonatal period on formalin pain behaviour and thermal withdrawal latencies. Pain Res Manage $2003 ; 8(4): 213-217$.

Preterm infants undergoing untreated, repeated painful procedures as part of their early experience are more likely to behave differently to pain as they mature than infants who were born at term and did not experience excessive exogenous pain. The neonatal rat model was used to investigate the short-and long-term effects of repeated pain in infancy on later development of pain responses. Newborn rat pups were randomly assigned by litter to be left unhandled (UH), handled by being removed from the dam for 15 min four times daily $(\mathrm{H})$, and being handled and receiving pain from a paw prick with a $26 \mathrm{G}$ needle four times daily (P) on postnatal days (PD) 2 through 8 (PD2-PD8). Maternal behaviour and grooming of pups on their return to the nest were recorded at PD6 for $\mathrm{H}$ and P pups. At PD15, PD36 and PD65, animals were first tested for latency to thermal stimulation threshold using the Hargreaves test and then for inflammatory pain using the formalin test. Pups in the HP group received significantly more grooming from their mothers (359 s) than pups in the H group (295 s, P<0.0001). When accounting for differences in maternal grooming, a decreased thermal threshold in the $\mathrm{P}$ group compared with the $\mathrm{H}$ group (6.04 s versus 5.3 $\mathrm{s}, \mathrm{P}<0.05)$ was found, although the correlations were not significant between maternal grooming and thermal thresholds. No group differences were seen with the formalin test. Interestingly, age was a significant factor in both tests, with younger animals showing fewer pain behaviours regardless of group or maternal grooming of the pup. Sex was significant at one age only in latency to thermal stimulation testing. The results suggest that changes in maternal care may be an important factor mediating the long-term effects of repeated neonatal experiences of pain.
Les effets de l'exposition à une douleur mineure répétée pendant la période néonatale sur le comportement à la douleur causée par le formaldéhyde et les latences au retrait thermique

Les prématurés qui subissent des interventions douloureuses répétées et non traitées au début de leur vie sont plus susceptibles de réagir différemment à la douleur en grandissant que les nourrissons nés à terme qui n'ont pas subi de douleur exogène excessive. Un modèle de rat néonatal a été utilisé pour explorer les effets à court et à long terme de la douleur répétée pendant la première enfance sur la réaction à la douleur plus tard. Les ratons nouveau-nés ont été séparés au hasard par portée pour demeurer non manipulés (NM), être manipulés en étant retirés de leur mère 15 minutes quatre fois par jour $(\mathrm{M})$ et être manipulés et exposés à la douleur d'une piqûre au moyen d'une aiguille $26 \mathrm{G}$ quatre fois par jour $(\mathrm{P})$ au cours des journées postnatales (JP) 2 à 8 (JP2-JP8). Le comportement maternel et les soins aux ratons à leur retour au nid ont été enregistrés la JP6 pour les ratons M et P. Les JP15, JP36 et JP65, les animaux ont d'abord subi un examen de latence au seuil de stimulation thermale au moyen du test de Hargreaves, puis à la douleur inflammatoire au moyen du test de formaldéhyde. Les ratons du groupe NM ont reçu beaucoup plus de soins de leur mère ( $359 \mathrm{~s}$ ) que ceux du groupe $\mathrm{M}(295 \mathrm{~s}, \mathrm{P}<0,0001)$. Au moment de comptabiliser les différences de soins maternels, une réduction du seuil thermique du groupe $\mathrm{P}$ a été constatée par rapport au groupe M (6,04 s par rapport à 5,3 s, P<0,05), bien que les corrélations entre les soins maternels et les seuils thermiques n'aient pas été significatifs. Aucune différence n'a été remarquée entre les groupes pour ce qui est du test de formaldéhyde. Il est intéressant de constater que l'âge était un facteur important dans les deux tests, les animaux plus jeunes affichant moins de comportements de douleur, quels que soient leur groupe ou les soins maternels reçus. Le sexe n'était significatif qu'à un âge précis pour ce qui est de la latence au test de stimulation thermique. Les résultats indiquent que les modifications des soins maternels peuvent être un facteur médiateur important sur les effets à long terme d'expériences néonatales répétées à la douleur.

Key Words: Animal models; Neonates; Procedural pain

Preterm infants who undergo untreated, repeated, painful
procedures as part of their early experience are more likely to behave differently to pain as they mature than infants who were born at term and did not experience excessive exogenous pain (1). Further support for the effects of painful procedures has been reported by Johnston and Stevens (2) who showed that a greater number of painful events experienced by 28-week postconceptual age preterm infants was associated with a blunting of pain response at 32 weeks postconceptual age. In addition, Grunau et al (3) showed a blunted pain response in infants who had not received morphine analgesia. Although human studies are directly relevant to the clinical problems of repeated pain in this population, many factors cannot be controlled, including the timing and magnitude of the painful events, the precise age of the infant, and all the concurrent health issues affecting the infant.

Animal models have recently been developed to mimic the repeated procedural pain experienced by preterm infants in the 
neonatal intensive care unit (NICU). The neonatal rat model is used because the development of the pain pathways in rats is believed to parallel that of humans in the last gestational trimester $(4,5)$. Thus far, there have been two published studies addressing the impact of repeated pain during this period on pain sensitivity and other related behaviours $(6,7)$. In a study by Anand et al (6), neonatal rats' paws were exposed to one, two or four needle sticks versus being touched with a cotton swab on separate paws daily for the first week of postnatal life. At postnatal days (PD) 16, PD22 and PD65, latency to thermal stimulation thresholds were tested using the hot plate test, and other behaviours related to stress were recorded in adulthood (PD65). The pups who had received pain four times daily showed decreased pain threshold at PD16 and PD22, but not as adults. As adults, those subjected to neonatal pain showed an increased preference for alcohol and increased emotionality in the open field test, but normal adrenocorticotropic hormone and corticosterone responses to the stress of air puff startle. In a study by Anisman et al (8), newborn rat pups were injected once with an inflammatory agent that resulted in edema, erythema and pain behaviour for a week. As adults, the rats that had received the inflammatory agent showed increased sensitivity to the formalin test, a test of inflammatory pain. More importantly, there were changes in the neurons, specifically, in the abnormal sprouting of fibres and in the distribution of nociceptive receptors in the dorsal root ganglia of the spinal cord, supporting the idea that prolonged neonatal inflammation and pain can result in permanent alterations of nociceptive neural circuitry.

There are important methodological considerations in each of these studies. The particular model of the injection of an inflammatory agent that causes extreme pain behaviours (eg, paw lifting, licking, shaking) for a week in the life of a neonatal rat is extreme and likely results in neuropathies that are significantly more profound than would be seen in infants in the NICU. The first pain model described (6), while more akin to the pain experienced by preterm human neonates in the NICU, did not account for changes in maternal behaviour toward the pups as a result of daily maternal separation. As previously described, neonatal handling during the first 10 days of life can have profound effects on both immediate and subsequent behaviours (8-11). Handled rats display attenuated neuroendocrine and sympathetic nervous system responses to stressors compared with nonhandled animals (12-15), as well as reduced anxiety and better coping skills in adulthood compared with unhandled rats (16). Pain as a stressor might be affected by maternal behaviour. Consequently, changes in maternal behaviour triggered by painful neonatal procedures are critical to determine the direction of the long-term effects of pain observed in adult animals.

The purpose of the present study, therefore, was to test the effect of repeated pain in the neonatal period on later pain sensitivity. We also controlled for the effects of modified maternal care on these variables. To test whether the development of pain mechanisms is preferentially altered by neonatal manipulations, we used two different pain modalities: a thermal and an inflammatory stimulus. In the latency to thermal stimulation paradigm (Hargreaves test), the response is a reflexive withdrawal of the paw from the heat stimulus, which we believe to be mediated at the spinal cord. In the inflammatory pain model, more complex behaviours such as paw licking comprise the responses, and thus, are considered to be mediated at a supraspinal level.

\section{MATERIALS AND METHODS}

\section{Animals}

Pregnant Sprague-Dawley females were received in Douglas day 17 of gestation, and maintained under controlled conditions of light (12 h light, $12 \mathrm{~h}$ dark, lights on at 07:00), temperature $\left(21^{\circ} \mathrm{C}\right)$ and humidity, with food and water available ad libitum. On the day of birth, the litters were culled to 10 pups/mother with an equal ratio of males and females. Between PD2 to PD8, the entire litter of each dam was subjected to one of the following three treatments. The unhandled $(\mathrm{UH})$ group $(\mathrm{n}=40)$ was not handled except for cage cleaning once a week. In the handling (H) group $(n=46)$, pups were separated from their mothers and removed from their home cage for a total of $15 \mathrm{~min}$, and their hindpaws were rapidly dipped in $34^{\circ} \mathrm{C}$ water (the manipulated hindpaw [left or right] was alternated daily); pups were then placed in a fresh cage on a warming pad for $15 \mathrm{~min}$ before reunion with their mothers. This procedure was repeated four times daily at $3 \mathrm{~h}$ intervals starting at 09:00. In the pain (P) group $(\mathrm{n}=44)$, pups received the same treatment as the $\mathrm{H}$ group except that their hindpaws were pricked with a $26 \mathrm{G}$ needle after being dipped in water. Maternal behaviour (retrieval time, self-grooming, pup grooming and nesting time) was recorded and scored on PD6 for the first 30 min after reunion in the $\mathrm{H}$ and $\mathrm{P}$ groups.

Each group was then tested for pain responses during the neonatal (PD14 to PD16) and juvenile prepubertal (PD35 to PD37) periods and in adulthood (PD64 to PD66). Rats were first subjected to the Hargreaves test for latency to thermal stimulation threshold and, two to seven days later, for their pain behaviour in the formalin test. All procedures were approved by the Animal Care Committee at McGill University and followed ethical recommendations from the Canadian Council on Animal Care.

\section{Hargreaves (hot paw) testing}

On PD14 to PD16, PD35 to PD37 and PD64 to PD66, rats were tested using the Hargreaves test (17). In this test, the rat is placed in a Plexiglas box and left to habituate to the novel environment for $5 \mathrm{~min}$. A beam of light with a rapidly rising temperature is shone through a glass panel onto one paw on the thickest part of the padding. The beam is calibrated to provide an incremental temperature of $0.82 \pm 0.1^{\circ} \mathrm{C}$ per second and the starting temperature is $21^{\circ} \mathrm{C}$ (room temperature). Latency to lifting the paw is an indication of pain threshold. Five consecutive trials were administered for each paw, alternating paws with an intertrial interval of $2 \mathrm{~min}$ to $3 \mathrm{~min}$. Because there were no differences between left and right paws, the data were collapsed and latency measures were averaged for each pup over the trials.

\section{Formalin test}

Rats were injected in the right hindpaw with $10 \mu \mathrm{L}$ of either vehicle $(0.9 \%$ saline) or formalin ( $1 \%$ for PD14 to PD16; $2.5 \%$ or 5\% for PD35 to PD37 and PD64 to PD66) and immediately placed in an observation cage where pain behaviours were scored for $30 \mathrm{~min}$ according to procedures described in earlier work in neonates and adults with similar formalin concentrations 
TABLE 1

Duration of maternal behaviours: Pup grooming and nesting at return to nest

\begin{tabular}{lccc}
\hline Group & $\mathbf{n}$ & $\begin{array}{c}\text { Pup grooming } \\
\text { (mean } \pm \text { SD) }\end{array}$ & $\begin{array}{c}\text { Nesting } \\
\text { (mean } \pm \text { SD) }\end{array}$ \\
\hline Handled & 52 & $294.7 \pm 37$ & $962.6 \pm 40$ \\
Pain & 51 & $359.2 \pm 105$ & $936.7 \pm 43$ \\
\hline
\end{tabular}

Average amount of time in seconds spent by dams grooming pups or nesting in the first half hour from return of pups to nest following handling or pain interventions at postnatal day 6. Analysis of variance for pup grooming $F(1,101)=17.402, P<0.0001$

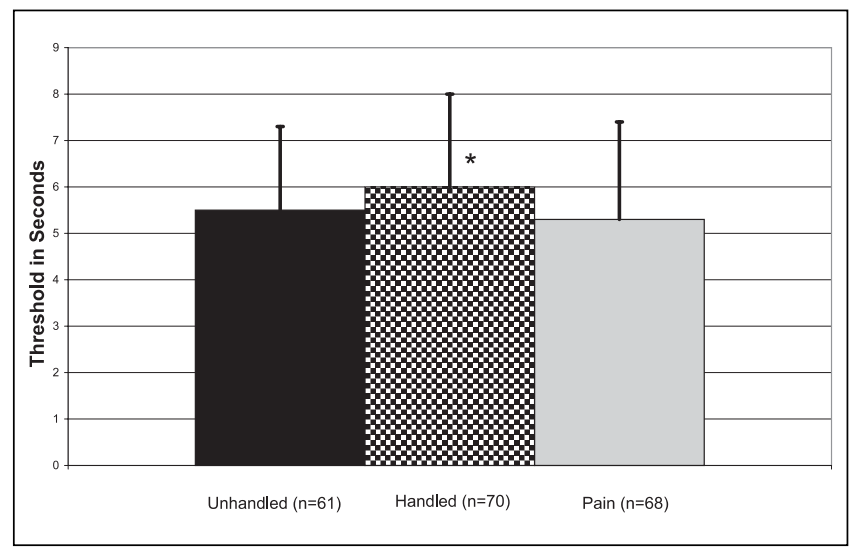

Figure 1) Hargreaves scores by group. Comparison of threshold latency to thermal paw stimulation in seconds. *The handled group had significantly higher thresholds than the pain group when maternal grooming was a covariate (analysis of covariance $F[2]=3.94, P<0.049$ )

(18). Briefly, rats were scored for specific pain behaviours (normal paw, favour, lift, lick/shake/flinch paw in increasing order of magnitude), general behavioural state (sleep, groom, locomotion, etc) and 'physiological' state (normal, piloerection, sickness behaviour). According to an earlier report (19), most of these behaviours are already observed in the neonatal period and the formalin concentrations that were used in the present study (intended to provide $40 \%$ to $50 \%$ of pain behaviours at each age [20]) provide the best sensitivity for the behavioural measures.

\section{Statistical analysis}

All results were initially determined by descriptive statistics, correlational coefficients and analysis of variance (ANOVA) using treatment group (UH, H, P) and age (PD15, PD35, PD60) as factors. Duration of maternal grooming of the pups at reunion on PD6 was used as a covariate in an analysis of covariance (ANCOVA) for the pups in the $\mathrm{H}$ and $\mathrm{P}$ groups only because there were no data on UH pups who had not been separated and, thus, had no reunion.

\section{RESULTS}

Maternal behaviours

Maternal grooming of pups was significantly greater in the $\mathrm{P}$ group than in the $\mathrm{H}$ group (means $359 \mathrm{~s}$ versus $295 \mathrm{~s}$, $\mathrm{F}[1,101]=17.4, \mathrm{P}=0.0001$ ), but nesting was similar in both groups (963 s versus 937 s) (Table 1).

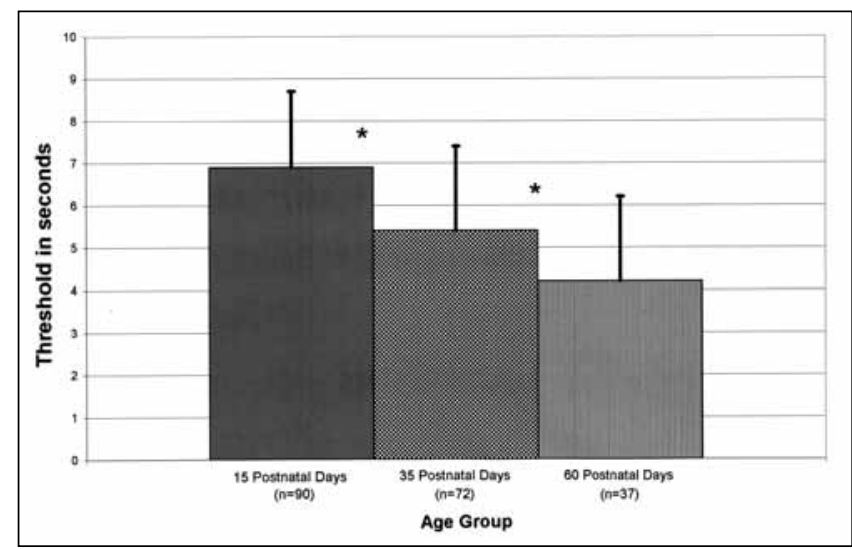

Figure 2) Hargreaves scores by postnatal age. Comparison of threshold latency to thermal paw stimulation in seconds. *The thresholds decreased significantly as the pups aged (analysis of variance $F[1,2]=52.987, P<0.00001)$, with post hoc tests showing significant differences between all age groups

\section{Hargreaves test}

The only significant difference in the Hargreaves scores between groups was a lower threshold for the $\mathrm{P}$ group than for the $\mathrm{H}$ group, but only when the amount of maternal grooming of pups was taken into account through ANCOVA (6.03 s versus $5.3 \mathrm{~s}, \mathrm{~F}[2]=3.94, \mathrm{P}<0.049$ [Figure 1]). This was in spite of the fact that the correlations between maternal grooming and outcomes were not significant. There were significant age group differences, with the thresholds decreasing in each age group (Figure 2). There were no significant interaction effects between test group and age ( $\mathrm{F}=0.335$, $\mathrm{P}$ not significant $)$. There was also a significant difference over day of testing, with the threshold increasing at each test time. Pup grooming was not a significant covariate.

\section{Formalin test}

The rats who were injected with vehicle showed no pain behaviours and were excluded from the analyses. There were no significant intervention group differences (Figure 3) at any ages. There were significant age differences, with the younger age group showing less painful paw behaviour (17 min of pain paw behaviours) than the older groups ( $53 \mathrm{~min}$ and $56 \mathrm{~min}$ of pain paw behaviour; $F[2]=48.69, \mathrm{P}<0.0001$ ) (Figure 4). There were no significant interaction effects between test group and age ( $\mathrm{F}=0.600, \mathrm{P}$ not significant). There were no sex differences ( $F=0.872$, P not significant). Taking the amount of pup grooming into account increased the mean differences between the two groups, although not significantly, and the amount of pup grooming was not significant as a covariant in ANCOVA ( $\mathrm{F}=0.084$, P not significant).

\section{DISCUSSION}

Based on the results of this study, it cannot be concluded that early exposure to minor repeated pain always results in longterm consequences. The results of this study are different from earlier reports by Anand et al (6) and Ruda et al (7). The current study introduced a group to control for handling and maternal separation, and although there was a trend toward the $\mathrm{P}$ group being more sensitive, the only significant differences 


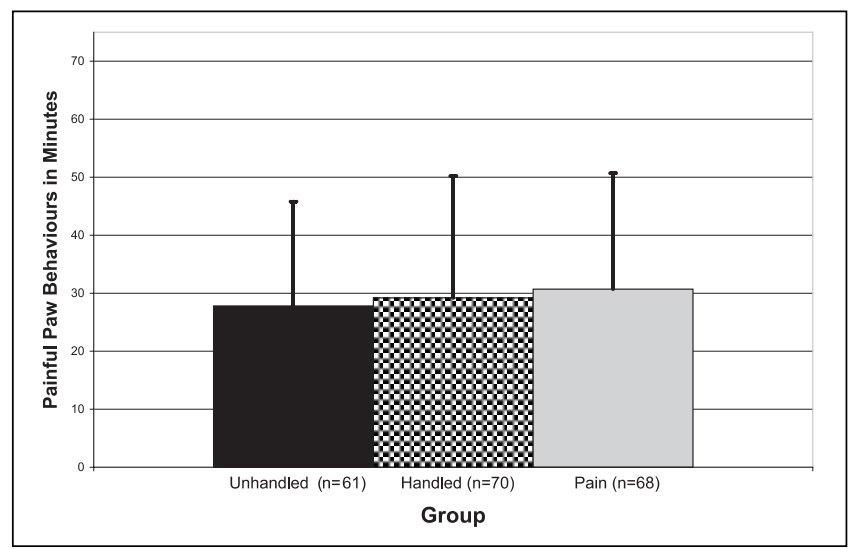

Figure 3) Formalin test results by group. Number of minutes animals displayed the paw pain behaviours of favouring, lifting or licking their paw following formalin injection into the hindpaw. There were no significant differences between groups, even when controlling for maternal behaviours

between any of the groups was in the Hargreaves hot paw test, and only when the amount of maternal grooming of pups was taken into account. More important differences were found in the age at which the pups were tested, with younger animals being less sensitive than older animals in both the formalin and the hot paw tests, regardless of group or maternal grooming of pups.

There needs to be more discussion regarding the appropriate animal model of repeated pain in early life, including the stimulus, the outcomes and the factors to be controlled. For example, complete Freunds adjuvant used by Ruda et al (7) produces visibly clear permanent tissue damage to the entire limb, as opposed to a needle stick. Anand et al (6), like ourselves, used repeated needle sticks but used different outcomes, with the exception of the hotplate, which is a measure of latency to thermal stimulation threshold similar to the Hargreaves test. This was the one situation in the current study in which there were significant effects, but only between $\mathrm{H}$ and P groups and not the UH group, and only when maternal grooming of pups was included in the analysis. This effect may have been spurious because the relation between maternal grooming and thermal threshold was not significantly correlated. The outcomes in this study were only related to subsequent pain behaviours, not to broader effects such as those reported by Anand et al (6), and, thus, we might have missed effects. In particular, we did not examine any physiological parameters that were examined in previous studies, and which should be included in future studies. Other factors, including maternal behaviour, need to be included in the testing paradigm. For example, maternal suckling has been shown to have a blunting effect in the immediate response to pain (21). By not controlling for maternal separation, the effects reported by Anand et al (6) could possibly have been due as much to maternal separation as to pain. To determine if the covariate effect we found was true, future studies should include a longitudinal assessment of maternal behaviour over several days of the procedure rather than observation of only one day of maternal behaviour at reunion. Finally, it is interesting how profound the effect of age was in both pain tests in this study. The youngest pups

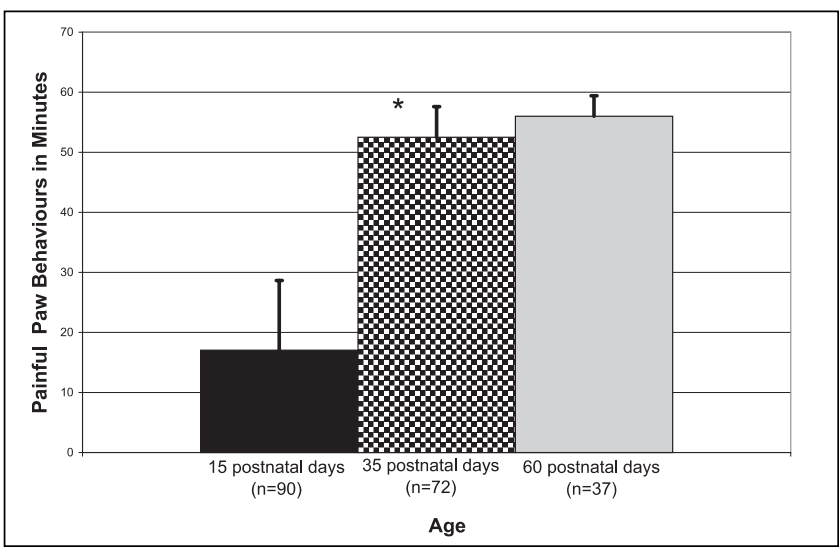

Figure 4) Formalin test results by age. Number of minutes animals displayed the pain behaviours of favouring, lifting or licking their paw following formalin injection into the hindpaw. The youngest pups showed significantly more normal paw, ie, less painful paw behaviours than the older pups (analysis of variance F[2]=48.69, $\mathrm{P}<0.0001$ ). * Significant

showed much greater tolerance to pain than the older rats, regardless of pain or maternal separation experience. There were no age by group effects in the current study, although Anand et al (6) reported that the effect of pain was only seen in the oldest group (adult) rats. Age has been reported to be important in the response to inflammatory pain (20), with younger animals showing a monophasic response as opposed to the biphasic response seen in adult animals, which was also found in this study. Similar to another study (6), we found sex not to be an influential factor in young animals' response to acute pain.

\section{CONCLUSION}

It seems that there is little support for the proposition that there is a decrease in threshold in latency to thermal stimulation in adulthood following repeated minor tissue injury in the neonatal period. There is a possibility that maternal behaviour may mediate the longer term effect of pain. Future research needs to include maternal behaviour as a factor influencing later pain sensitivity, but there may also be other mediating factors yet to be identified that are important in using animal models. Using animal models of pain in the neonatal period is appealing for ethical and control reasons, but these models require more refinement and testing before implications for human practice can be concluded from them.

ACKNOWLEDGEMENTS: We wish to thank Kristin Kudreikis for her excellent work in running many of the experiments. This study was supported by the Canadian Institutes of Health Research (MRC MOP-38074) and FRSQ (career award to CDW).

\section{REFERENCES}

1. Grunau RE. Long-term consequences of pain in human neonates. In: Anand KJS, Stevens BJ, McGrath PJ, eds. Pain in Neonates. Amsterdam: Elsevier, 2000:55-76.

2. Johnston CC, Stevens BJ. Experience in a neonatal intensive care unit affects pain response. Pediatrics 1996;98:925-30.

3. Grunau RE, Oberlander TF, Whitfield MF, Fitzgerald C, Lee SK. Demographic and therapeutic determinants of pain reactivity in very 
low birth weight neonates at 32 weeks' postconceptional age. Pediatrics 2001;107:105-12.

4. Narsinghani U, Anand KJS. Developmental neurobiology of pain in neonatal rats. Lab Animal 2000;29:27-39.

5. Fitzgerald M, Shaw A, MacIntosh N. The postnatal development of the cutaneous flexor reflex: A comparative study in premature infants and newborn rat pups. Dev Med Child Neurol 1988;30:520-6

6. Anand KJS, Coskun V, Thrivikraman KV, Nemeroff CV, Plotsky PM. Long-term behavioral effects of repetitive pain in neonatal rat pups. Physiol Behav 1999;66:627-37.

7. Ruda MA, Ling Q-D, Hohmann AG, Peng BP, Tachibana T. Altered nociceptive neuronal circuits after neonatal peripheral inflammation. Science 2000;289:628-31.

8. Anisman H, Zaharia MD, Meaney MJ, Merali Z. Do early-life events permanently alter behavioral and hormonal responses to stressors? Int J Dev Neurosci 1998;16:149-64.

9. Caldji C, Tannenbaum B, Sharma S, Francis D, Plotsky PM, Meaney MJ. Maternal care during infancy regulates the development of neural systems mediating the expression of fearfulness in the rat. Proc Nati Acad Sci U S A 1998;95:5335-40.

10. Liu D, Diorio J, Tannenbaum B, et al. Maternal care, hippocampal glucocorticoid receptors, and hypothalamic-pituitary-adrenal responses to stress. Science 1997;277:1659-62.

11. Meaney MJ, Aitken DH, Bodnoff SR. The effects of postnatal handling on the development of the glucocorticoid receptor systems and stress recovery in the rat. Prog Neuropsychopharmacol Biol Psychiatry 1985;9:731-4

12. Viau V, Sharma S, Plotsky PM, Meaney MJ. Increased plasma ACTH responses to stress in nonhandled compared to handled rats require basal levels of corticosterone and are associated with increased levels of ACTH secretagogues in the median eminence. J Neurosci 1993;13:1097-105.

13. Levine S, Haltmeyer GC, Karas GG, Denenberg VH. Physiological and behavioral effects of infantile stimulation. Physiol Behav 1967;2:55-9.

14. Vallee M, Mayo W, Dellu F, Le Moal M, Simon H, Maccari S. Prenatal stress induces high anxiety and postnatal handling induces low anxiety in adult offspring, correlation with stress-induced corticosterone secretion. J Neurosci 1997;17:2626-36.

15. Meerlo P, Horvath KM, Nagy GM, Bohus B, Koolhaas JM. The influence of postnatal handling on adult neuroendocrine and behavioral stress reactivity. J Neuroendocrinol 1999;11:925-33.

16. Walker CD, Plotsky PM. Corticosteroids, stress, and development In: Pfaff D, Arnold A, Farbach S, Rubin R, eds. Hormones, Brain, and Behavior. San Diego: Academic Press, 2002:487-53.

17. Hargreaves K, Dubner R, Brown F, Flores C, Joris J. A new and sensitive method for measuring thermal nociception in cutaneous hyperalgesia. Pain 1988;32:77-88.

18. Abbott FV, Franklin KBJ, Westbrook RF. The formalin test: Scoring properties of first and second pain responses in rats. Pain 1995;60:91-102.

19. Guy ER, Abbott FV. The behavioral response to formalin in preweanling rats. Pain 1992;51:81-90.

20. Teng CJ, Abbott FV. The formalin test: A dose-response analysis at three developmental stages. Pain 1998;76:337-47.

21. Blass EM, Shide DJ, Zaw-Mon C, Sorrentino J. Mother as shield: Differential effects of contact and nursing on pain responsivity in infant rats evidence for nonopioid mediation. Behav Neurosci 1995;109:342-53 


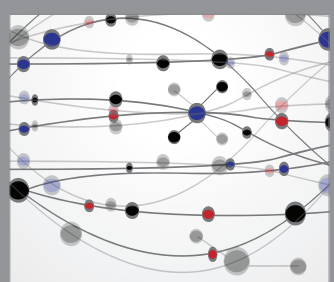

The Scientific World Journal
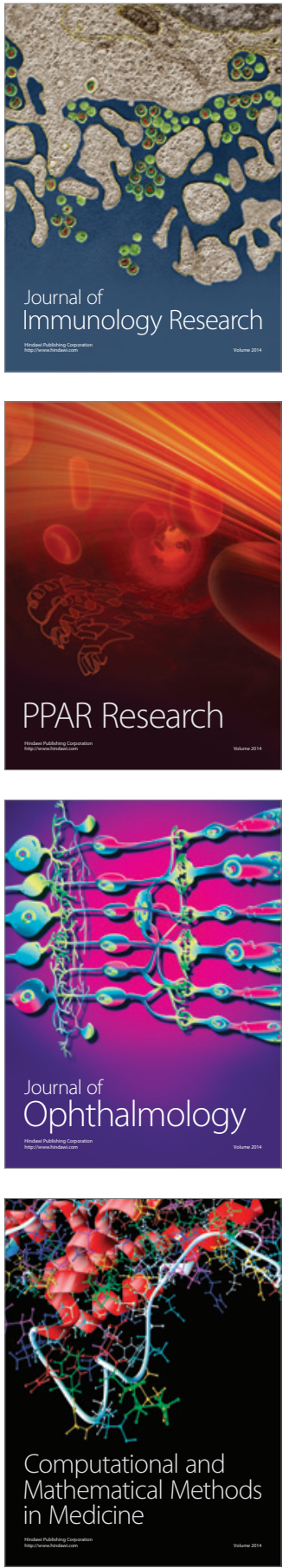

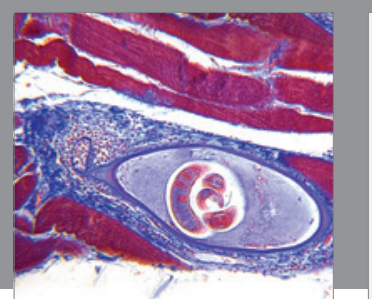

Gastroenterology Research and Practice

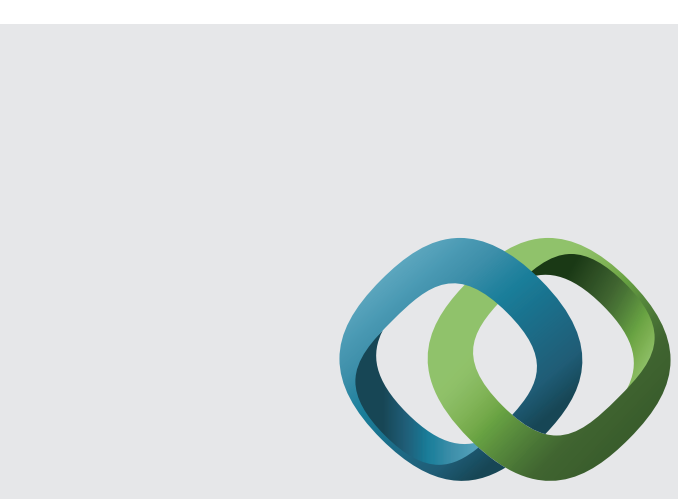

\section{Hindawi}

Submit your manuscripts at

http://www.hindawi.com
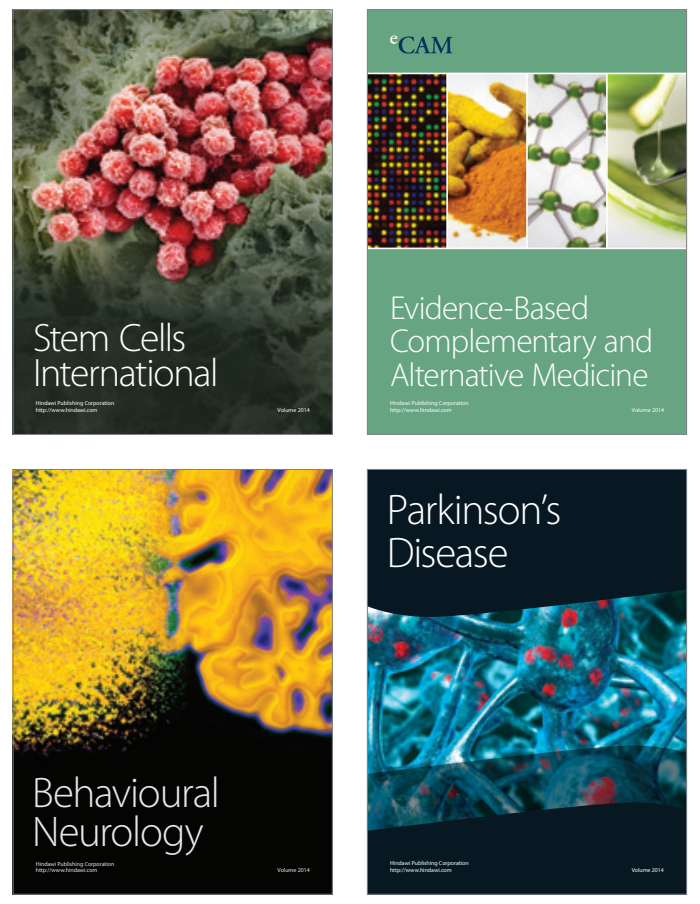
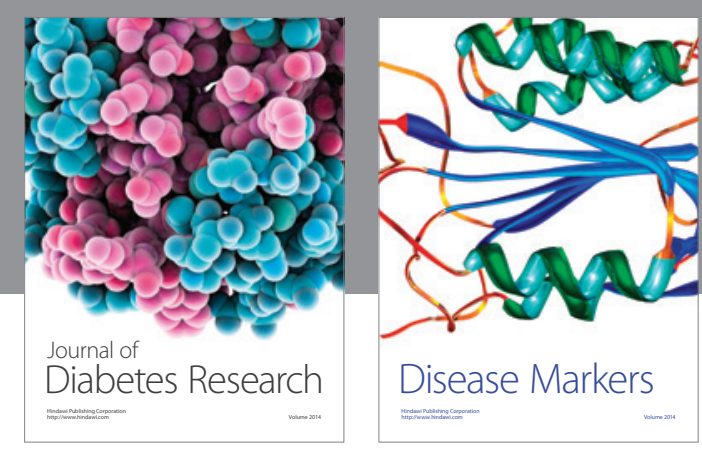

Disease Markers
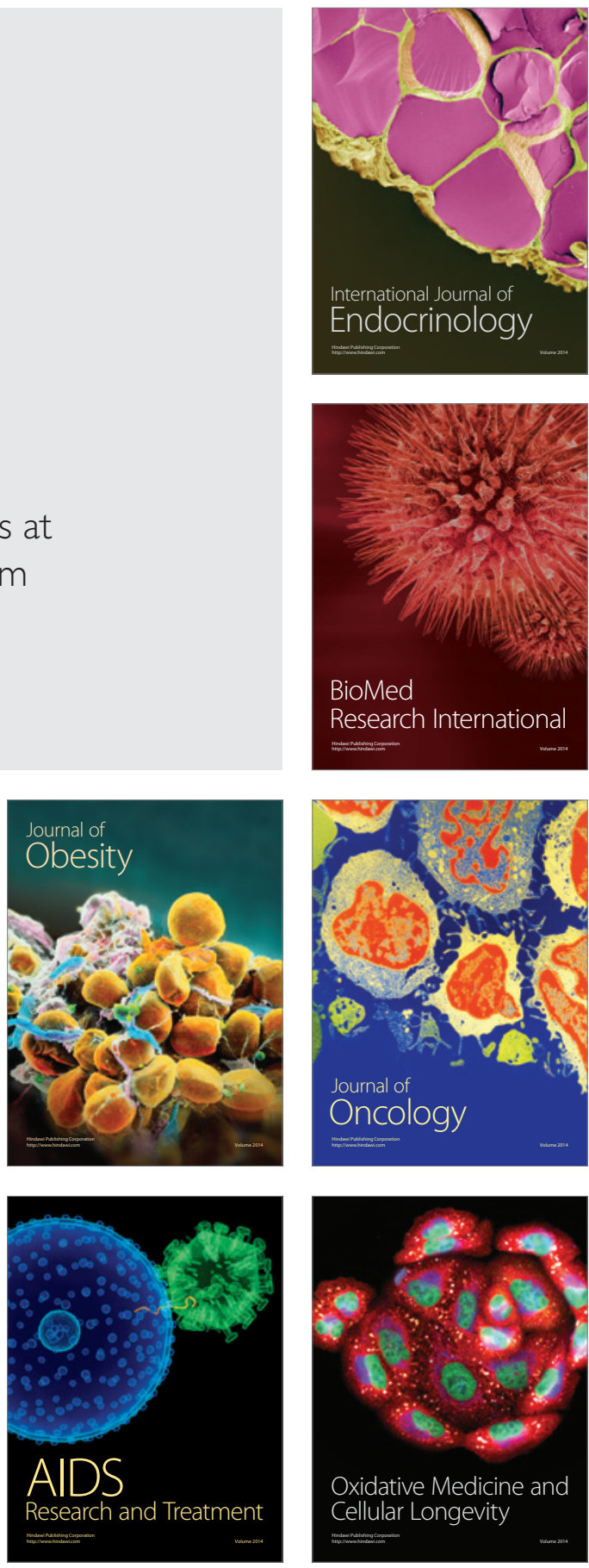